\title{
Asymmetric Intermixing and the Stress Buildup in Ni/Al-typed Nanomultilayer with Different Characteristic Scales
}

\author{
Liu Mingxia', Ma Fei ${ }^{2}$, Chang Gengrong1, He Binfeng', Fu Fuxing ${ }^{1}, \quad$ Ye Fangxia ${ }^{1}$, \\ Yu Lijun', Dai Jun', Xu Kewei ${ }^{1,2}$ \\ ${ }^{1}$ Shaanxi Key Laboratory of Surface Engineering and Remanufacturing, Xi'an University, Xi'an 710065, China; ${ }^{2}$ State Key Laboratory for \\ Mechanical Behavior of Materials, Xi'an Jiaotong University, Xi'an 710049, China
}

\begin{abstract}
In order to detect scale-dependent interfacial evolution of metallic heterostructure during the deposition at room temperature, Ni/Al-typed nanomultilayers were prepared as a function of the periodicity and Ni:Al modulated ratio. Combined with $\mathrm{X}$-ray diffraction, real-time plate curvature measurements by multi-beam optical stress sensor (MOSS) were employed to study the stress buildup so as to speculate interfacial characteristics during the growth process. Results show that with anisotropic nanocrystalline structure within the sub-layers, the multilayers possess asymmetrical interfaces, which is a result of dissymmetrical diffusion of $\mathrm{Ni}$ to $\mathrm{Al}$ lattice near the interface. Specially, for the smallest periodicity with the lowest $\mathrm{Ni}$ :Al ratio, above asymmetric intermixing behaviors turns to be aggravated by a promotion effect.
\end{abstract}

Key words: metal nanomultilayer; stress buildup; dissymmetrical diffusion; promotion effect

Nanomultilayered materials have become one of the significant research topics in recent years because of their potential applications in X-ray reflectors ${ }^{[1,2]}$, thin film magnetic recording media ${ }^{[3,4]}$, optoelectronics coatings ${ }^{[5]}$, wear resistance coatings ${ }^{[6,7]}$, strained quantum-well field-effect transistors $^{[8]}$, and Micro-Electro-Mechanical System (MEMS) structures $^{[9]}$. On the nano-meter scale, due to a high density of interfaces in multilayered system, large proportions of atoms are in close proximity with hetero-interfaces. This may change the energetics and atomic bonding dramatically and even exerts adverse effects on performance and reliability of devices ${ }^{[10]}$. Consequently, understanding the genesis of interfacial characteristics at smaller scale is indispensable from the perspective of both science and technical applications.

Particularly, as the ranges of characteristic length and of size parameter overlapped in a nano-meter range, the interfacial characteristics do become more complex, which would dominate the physical behavior of metallic multilayers $^{[11-14]}$. For instance, below certain length scale, many anomalous supermodulus and superhardness effect in several metallic multilayers including Ni-Cu${ }^{[11]}, \mathrm{Cu}-\mathrm{Au}^{[12]}$, and $\mathrm{Cu}-\mathrm{Nb}^{[14,15]}$, have been reported. Thereinto, Cammarata and Sieradzki found out the interface stress can cause perceptible changes in the lattice parameters of ultrafine microstructures in the artificial multilayers ${ }^{[15]}$ which might be contributed to above enhancement of compound moduli. Theoretically, Hoagland et al examined the resistance glide behaviors posed by coherent and semi-coherent interfaces by the atomic simulation methods ${ }^{[16]}$, and concluded that the core structure near the interfaces plays an important role in affecting the upper bound strengthening behavior. On the other hand, anomalous behaviors of electronic transport in ultra-thin metallic nanomultilayer are more complicated, for an increase interface scattering potential due to an intermixing effects with

Received date: March 25, 2016

Foundation item: National Natural Science Foundation of China (51271139, 51471130); Natural Science Foundation of Shaanxi Province (2013JM6002, 14JK2122); Fundamental Research Funds for the Central Universities; Xi'an Science and Technology Plan Projects (2016CXWL27)

Corresponding author: Liu Mingxia, Ph. D., Senior Engineer, School of Mechanical \& Material Engineering, Shaanxi Key Laboratory of Surface Engineering and Remanufacturing, Xi'an University, Xi'an 710065, P. R. China, E-mail: liumingxia1121@163.com 
decreasing of the periodicity ${ }^{[13,17,18]}$. As both of the interfacial feature and the size have an impact on the physical properties of nanomultilayers, in-depth study and proper control of their characteristic parameters and interfacial feature is of paramount importance to expand the applications of metallic nanomultilayers.

So, a lot of progress has been made recently in understanding the scale-dependent interfacial feature of multilayers in the nano-meter scale ${ }^{[19-22]}$. In fact, the interfaces would be affected by numerous factors including self-diffusion velocity ${ }^{[23]}$, surface stress of component part ${ }^{[24,25]}$, and even the segregation of element near the interface ${ }^{[26]}$. However, previous studies mostly focused on the diffusion velocity of the component element in multilayers ${ }^{[21,22]}$, regardless of the interface stress. Meanwhile, in recent investigations, many efforts have been devoted to the size effect mainly arising from the periodicity ${ }^{[11-18]}$, that is to say, the sub-layer thickness. Till now, the modulated ratio, being another important length scale of the multilayer, is always ignored especially when the fabrication of samples is generally exposed to a nonequilibrium state, such as the sputtering ${ }^{[27]}$. So, the purpose of this study is twofold: (1) to get direct interface stress so as to obtain the practical diffusion behavior in the as-grown multilayers, and (2) to study more detailed information on the interfacial structure with different characteristic scales of multilayers. Among metallic multilayered materials, Ni-based or Al-based components are of great potential for wide applications ${ }^{[6,11,23]}$. It is believed that the composite of $\mathrm{Ni}$ and $\mathrm{Al}$ would become an attractive candidate in advanced microelectronics ${ }^{[28]}$. More important is that there is large lattice parameter misfit and diffusion velocity between $\mathrm{Ni}$ and $\mathrm{Al}^{[29-31]}$. As a result, to fulfill above objectives we chose the $\mathrm{Ni}-\mathrm{Al}$ system and present the growth stress buildup and lattice variations by means of X-ray diffraction combined with real-time plate curvature measurement. By analyzing the resulting stress-thickness curves and lattice variations at representative scales, we attempt to find an intrinsic physical mechanism which can be used to comprehensively evaluate the influences of all factors on the interfacial structure of nanomultilayers, including interface stress, periodicity, and modulated ratio.

\section{Experiment}

The Ni/Al multilayers described here have been grown via power-regulated $d c$ magnetron sputtering onto a silicon substrate with native silicon oxide on the surface. The substrate was cleaned in acetone and alcohol ultrasonic baths before sputtering. The sample chamber was evacuated to a pressure lower than $3 \times 10^{-4} \mathrm{~Pa}$ prior to filling with $99.999 \%$ pure argon gas to $0.3 \mathrm{~Pa}$. The targets were cleaned with sputtered Ar ions prior to deposition, while the substrate was isolated from the plasma by a stainless-steel shield. The deposition was performed at room temperature and the substrate was cooled by circulating water. The sputtered targets of $\mathrm{Ni}$ and $\mathrm{Al}$ were $99.99 \mathrm{wt} \%$ in purity. To improve film oxidation resistance, $\mathrm{Ni}$ layer was placed on the top of multilayers in all samples and it was also firstly sputtered onto the substrate as an underlayer to prevent the interdiffusion between $\mathrm{Al}$ layer and $\mathrm{Si}$ substrate. For comparison, three series of deposited $\mathrm{Ni} / \mathrm{Al}$ multilayers were synthesized with the same total thickness of approximately $500 \mathrm{~nm}$. The periodicity $L$ was varied from several nanometers to tens of nanometers by controlling the sputtering time with a computer procedure. The three series differed with the Ni:Al modulated ratio $r$ as 1:2, 1:1, and 2:1.

$\mathrm{X}$-ray diffraction (XRD) was carried out on a Rigaku $7000 \mathrm{~S}$ diffractometer with a $\mathrm{Cu} \mathrm{K} \alpha$ radiation and a graphite monochromator to determine the out-of-plane interplanar spacing of the multilayers. The primary surface and crosssection morphologies of the multilayers were characterized on a field-emission scanning electronic microscopy (FESEM) using a JEOL JSM-6700F.

The stress measurements were made in real time during magnetron sputtering growth using a multi-beam optical stress sensor (MOSS). The sample curvature has been measured during the growth of several Ni/Al multilayers $(L=10 \mathrm{~nm}$ and $r=1: 1)$ depositions. Then, the curvature $k$ could be measured by monitoring the deflection of a set of initially parallel laser beams after reflection from the substrate. Because a thin film in a state of biaxial stress produces a curvature of the underlying substrate, for purely elastic growth of uniform-multilayer $\mathrm{Ni}-\mathrm{Al}$ system at constant rate $r_{0}$, the curvature $\kappa$ is related to the film stress $\sigma$ as

$$
F=\frac{1}{6} \cdot M_{\mathrm{s}} l_{\mathrm{s}}^{2}(\mathrm{~d} \kappa / \mathrm{d} t)
$$

where $F$ is the force per unit width applied during the deposition, $l_{\mathrm{s}}$ is the substrate thickness and $M_{\mathrm{s}}$ is the biaxial modulus of the Si substrate: $M_{\mathrm{s}}=180$ or $229 \mathrm{GPa}$ for $\mathrm{Si}(001)$ or $\operatorname{Si}(111)$, respectively ${ }^{[32]}$.

\section{Results and Discussion}

For the deposited $\mathrm{Ni} / \mathrm{Al}$ multilayer samples at room temperature, we obtain plane and cross-sectional views by the employment of FESEM measurements. A typical plan-view of the Ni/Al multilayer (seen in Fig.1a) shows that the top $\mathrm{Ni}$ layer has in-plane grains about several tens of nanometers or so in diameter, indicating that the as-sputtered $\mathrm{Ni} / \mathrm{Al}$ film consists of alternatively layered $\mathrm{Ni}$ and $\mathrm{Al}$, and each sub-layer is composed of polycrystallites in nano-meter dimension. Fig.1b shows the cross-sectional image from Ni/Al multilayers. The multilayers show a well-defined layered structure, comprised of thick light gray $\mathrm{Ni}$ and thin dark gray $\mathrm{Al}$ sub-layers on the depth scale. Clearly, this laminar structure of $\mathrm{Ni} / \mathrm{Al}$ nanomultilayers reveals the fine modulated structures 


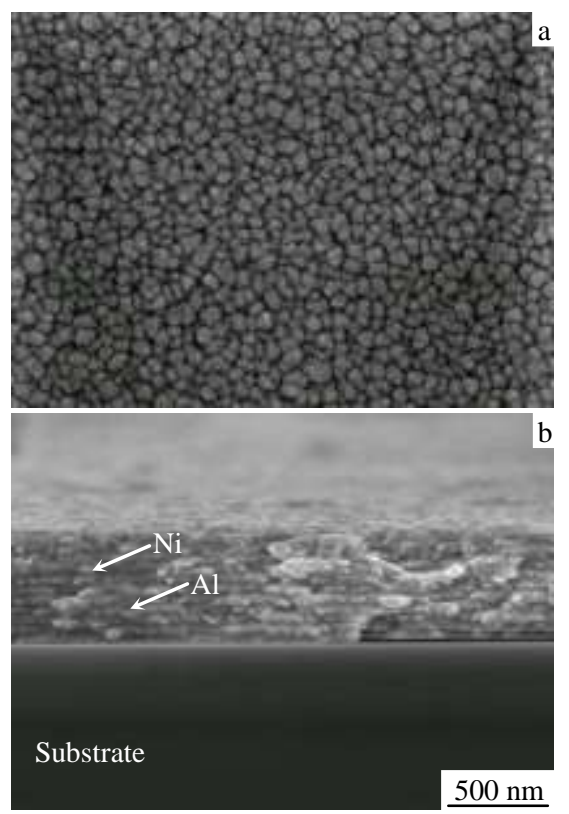

Fig.1 FESEM micrographs of as-deposited $\mathrm{Ni} / \mathrm{Al}$ multilayers on $\mathrm{Si}$ substrate with the total thickness of $500 \mathrm{~nm}$ and the periodicity $L$ of $42 \mathrm{~nm}$ with the $\mathrm{Ni}: \mathrm{Al}$ modulated ratio $r$ of 2:1: (a) plan-view of the multilayer surface and (b) cross-sectional view of the multilayer

formed during sputtering.

Fig.2 shows the typical high-angle XRD profiles of three series of as-sputtered $\mathrm{Ni} / \mathrm{Al}$ multilayers as a function of the periodicity $L$ with different Ni:Al modulated ratio $r$ of 1:2, 1:1, and 2:1. Only the diffraction angles from $30^{\circ}$ to $60^{\circ}$ are displayed for clarity. It can be exhibited that all of the samples are polycrystalline with predominant $\mathrm{Al}-(111)$ and $\mathrm{Ni}-(111)$ textures. This is typically accepted for sputter deposition of fcc metals on amorphous wafers ${ }^{[33]}$. The distinctness of the half-width at maximum profile of $\mathrm{Ni}-(111)$ and $\mathrm{Ni}-(200)$ implies the anisotropic feature of mean crystalline shape.
Obviously, in each series, the peaks of $\mathrm{Ni}$ and $\mathrm{Al}$ are weak and broad, which implies that under the experimental condition of this work, $\mathrm{Ni}$ and $\mathrm{Al}$ sub-layers exist as nanocrystal. This result is also confirmed by FESEM results in Fig.1a. Moreover, at constant $r$, the gradual increase in the half-width of $\mathrm{Al}-(111)$ and $\mathrm{Ni}-(111)$ peaks with the decrease of $L$ indicates that the thinner the film, the smaller the grain size. In addition, it is noted that the calculated mean grain size of metal $\mathrm{Ni}$ and $\mathrm{Al}$ by Scherrer formula is in a nano-meter region and especially smaller than the respective sub-layer thickness.

Additionally, as shown in Fig.2a and Fig.2b, the peak position of $\mathrm{Ni}$ phase deviates from the equilibrium state to lower-angle region, with no significant change of Al-(111) peaks. This deviation increases with the decrease of periodicity, indicating that the interplanar spacing of metal nickel perpendicular to the film plane might increase with decreasing periodicity, especially for the samples with the ratio of 1:2 and 1:1. Moreover, it is worthwhile noting that this shift is visible only when the periodicity is below a critical value (about $20 \sim 30 \mathrm{~nm}$ ) for a constant modulated ratio. This probably can be explained by the fact that this shift of the diffraction peak has the tight relationship with the particular interfacial feature, i.e., the intermixing phenomenon ${ }^{[18,27]}$. Furthermore, this mixing behavior shows scale dependence on the characteristics length scale including both the periodicity and the modulated ratio. It is necessary to study the interfacial feature for clarity above behaviors.

As the characteristic length scale shrinks down, the intermixing behavior turns to be prominent near the interface of Ni-Al system leading to a readjustment of the atoms. In such a case, considerable interface energy and interface stress are stored in the multilayers and the system equilibrium is perturbed. The atomic relaxation will subsequently take place to restore the equilibrium, especially in materials with feature sizes of only several atomic layers ${ }^{[34]}$. Therefore, the measurement on the relaxation of the initial atomic configuration at the interfaces of $\mathrm{Ni} / \mathrm{Al}$ multilayers is indispensable to clarity
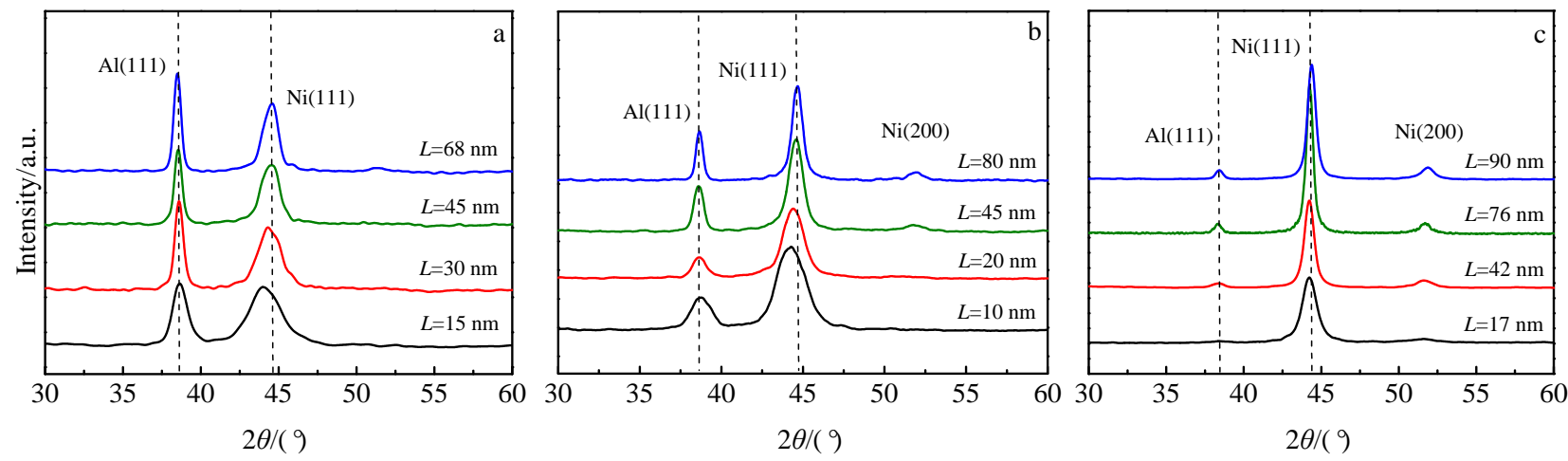

Fig.2 Representative XRD patterns of Ni/Al nanomultilayers as a function of periodicity $L$ with different Ni:Al modulated ratio $r$ of $1: 2$ (a), 1:1 (b), and 2:1 (c). (thereinto, dashed lines represent the standard line positions calculated from the perfect Ni-(111) and Al-(111) crystal lattices) 
the interfacial characteristic. Since the evolvement of interface stress has been mainly restricted into several nanometers near the hetero-interfaces or facets, our attention is conducted only on the adjacent interfaces in Ni-Al systems. The force $F$ is plotted against the deposited thickness in Fig.3a and Fig.3b for $\mathrm{Al}-\mathrm{Ni}(111)$ and $\mathrm{Ni}-\mathrm{Al}(111)$, respectively. In the present case the observed behavior does not depend on the bilayer number within the multilayer. The plots in Fig.3 are thus representative of typical $F(l)$ behaviors. Note that a large compressive force develops as a consequence of $\mathrm{Al}$ deposition on $\mathrm{Ni}(111)$, which is indeed in agreement with the size difference between $\mathrm{Al}\left(a_{\mathrm{Al}}=0.4049 \mathrm{~nm}\right)$ and $\mathrm{Ni}\left(a_{\mathrm{Ni}}=0.3523 \mathrm{~nm}\right)$.

On the other hand, the $\mathrm{Ni}$ growth on $\mathrm{Al}(111)$ behaves very differently. Although the tensile force is expected from size considerations, the initial horizontal tangent followed by an increase in Fig. $3 \mathrm{~b}$ seems very surprising. It is speculated that the initial zero stress is a result of $\mathrm{Ni}$ diffusion into $\mathrm{Al}$ which results in an out-of-equilibrium solid solution with an expanded average lattice parameters ${ }^{[18,34-36]}$. For a large misfit in lattice parameters and a positive enthalpy of mixing in $\mathrm{Ni}-\mathrm{Al}$ system, it is therefore expected that atomic exchange at the surface takes place. The rich-Ni phenomenon was also identified by EXAFS technique at the Ni $K$ edge $^{[35]}$. Meanwhile, the existence of a $\mathrm{Ni}$ concentration profile in $\mathrm{Al}$ surface has been evidenced using AES analysis ${ }^{[36]}$. More precisely, the shift of nickel peaks in Fig.2 is in agreement with this asymmetric diffusion behavior. It is worth noting that this experimental situation is far more complicated than the

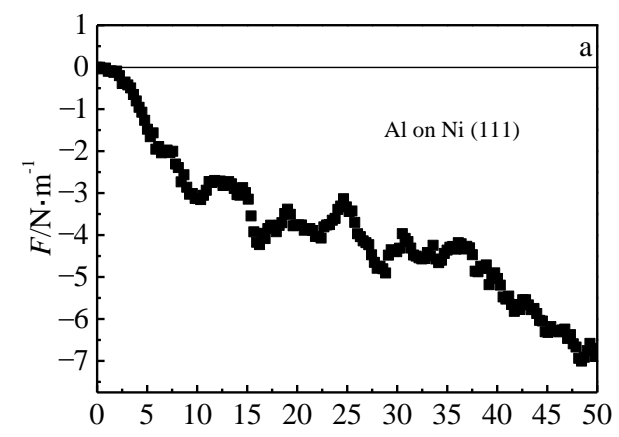

Al Thickness/ $\times 0.1 \mathrm{~nm}$

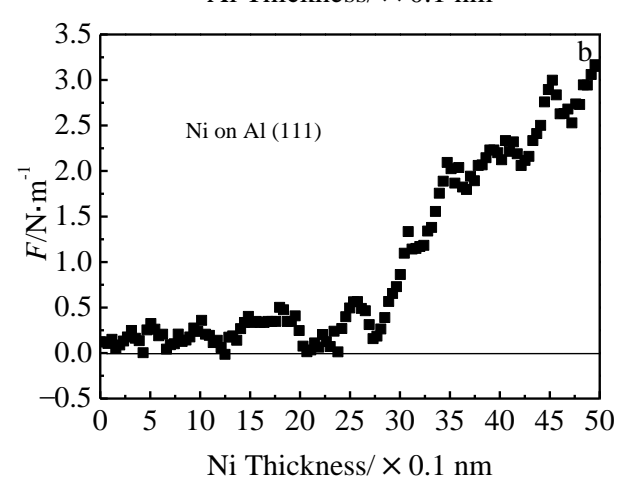

Fig.3 Force per unit width deduced from bending during the growth of $\mathrm{Al}$ on $\mathrm{Ni}(111)$ (a) and $\mathrm{Ni}$ on $\mathrm{Al}(111)(\mathrm{b})$ equilibrium interdiffusion one and leads in the presence of a $\mathrm{Ni}$ flux to an interfacial concentration gradient. This profoundly influences elastic stress buildup in the Ni layer, as shown in Fig.3b.

In order to investigate the scale-dependent intermixing phenomenon in Ni/Al multilayers, the lattice spacing $d_{111}$ (subscript denotes the crystal facet) perpendicular to the $\mathrm{Ni}$ film plane is calculated according to the Bragg equation, and plotted as a function of the reciprocal of the periodicity in Fig.4. Note that for $r$ equals to either $1: 2$ or $1: 1$, the $d_{111}$ values increase linearly with the increased $1 / L$ or the amount of interfaces. It is not sufficient only to discuss it thermodynamically, and it is also necessary to analyze the kinetic factor in the multilayer growth. Note that, as shown in Fig.4, the observation reveals the smaller $\mathrm{Ni}: \mathrm{Al}$ ratio, the heavier the diffusion extent below a critical value of periodicity. In vapor deposition, when the sputtered particles are deposited on the growth surface, they will be determined by the remaining energy, the substrate temperature, and also the characters of growing face, etc ${ }^{[3]}$. Thereinto, the feature of the growth face would exert strong effects on the mobility of the atoms during the deposition especially below certain characteristic length scale.

It is speculated that, as illustrated in Fig.5, when the thickness of $\mathrm{Ni}$ sub-layer shrinks down under a threshold value, not only the roughness of $\mathrm{Ni}$ layer becomes aggravated due to the diffusion of $\mathrm{Ni}$ into $\mathrm{Al}$ sub-layer, but also newly deposited Al layer grows roughly. Afterwards, the roughened surface of $\mathrm{Al}$ may enhance the exchange of $\mathrm{Ni}$ atoms with metal Al. Thus, this behavior would accelerate the roughening behavior of $\mathrm{Ni}-\mathrm{Al}$ interface and result in even a intermixing zone in Fig.5, due to a heavy prominent diffusion phenomenon. With the increase of $\mathrm{Ni}$ :Al ratio and periodicity, as shown in Fig.5c, the promotion effect becomes weaken or even disappears. This special behavior induced by accumulation effect has also been observed and verified in other metallic nanomultilayers deposited at room temperature ${ }^{[7,37,38]}$.

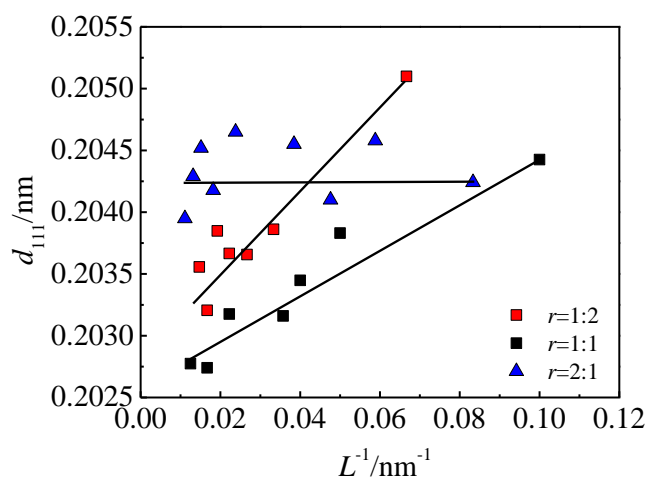

Fig.4 Out-of-plane interplanar spacing of $\mathrm{Ni}(111) d_{111}$ as a function of the reciprocal of the periodicity 


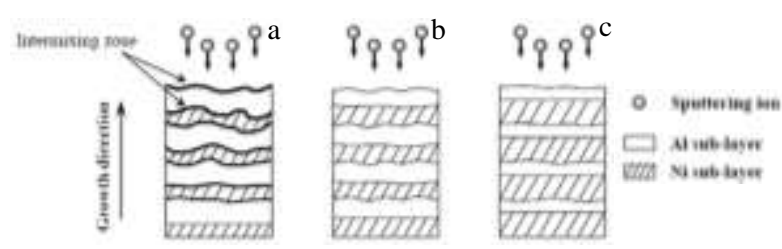

Fig.5 Illustration of Ni/Al multilayer with different Ni:Al modulated ratio $\mathrm{r}$ if below certain periodicity: (a) $r=1: 2$, (b) $r=1: 1$, and (c) $r=2: 1$

In fact, the mutual promotion effect becomes the key factor determining the electrical and mechanical properties of ultrathin metallic nanomultilayers on the nano-meter scale. So far, the results demonstrate that the interfacial diffusion behavior will be sensitive to the periodicity and the modulated ratio, and our simple model may clarify this scale-dependence. However, it should be noted that if composition material and deposition conditions are altered due to other factors, such as interface alloying, higher deposition temperature and impurity introduction, the morphology of the interfaces ought to change accordingly, and in-depth work is being conducted in our research group for verification.

\section{Conclusions}

1) $\mathrm{Ni} / \mathrm{Al}$ system is in a good compositionally modulated structure with numerous anisotropic nanocrystallines. The growth stress of $\mathrm{Al}$ (on $\mathrm{Ni}$ ) shows a large compressive force, whereas that of $\mathrm{Ni}$ (on $\mathrm{Al}$ ) exhibits a strong interplay between the stress and the interfacial mixing. Thus, a detailed analysis of the asymmetrical interfacial features identified $\mathrm{Ni}$ appears to be the moving element in the layered structures.

2) As a consequence of a mutual promotion effect, the asymmetric interdiffusion in Ni-Al system exhibits notable scale-dependence at smaller periodicity and modulated ratio. Significantly, our results provide insight to the diffusion behaviors of metallic nanomultilayers in multi-scale dimension.

\section{References}

1 Vo V T, Koon K L, Hu Z R et al. Applied Physics Letters[J], 2004, 84: 3073

2 Noro J, Ramos A S, Vieira M T. Intermetallics[J], 2008, 16: 1061

3 Albrecht M, Hu G, Guhr I L et al. Nature Materials[J], 2005, 4: 203

4 Bousquet E, Dawber M, Stucki N et al. Nature[J], 2008, 452(7188): 732

5 O'Hara J F, Zide J M O, Gossard A C et al. Applied Physics Letters[J], 2006, 88: 251119

6 Gavens A J, Heerden D V, Mann A B et al. Journal of Applied Physics[J], 2000, 87: 1255
7 Li G, Li Y, Li G. Applied Surface Science [J], 2011, 257: 5799

8 Kang T K, Huang P C, Sa Y H et al. Japanese Journal of Applied Physics [J], 2008, 47: 2664

9 Xue W, Cui T. Nanotechnology[J], 2007, 18: 145709

10 Ma F, Ma S L, Xu K W et al. Nanotechnology[J], 2007, 18: 445101

11 Hoagland R G, Mitchell T E, Hirth J P et al. Philosophical Magazine [J], 2002, 82: 643

12 Zhang G P, Liu Y, Wang W et al. Applied Physics Letters[J], 2006, 88: 013105

13 Zheng Z H, Fan P, Luo J T et al. Thin Solid Films[J], 2014, 562: 181

14 Misra A, Hirth J P, Hoagland R G. Acta Materialia[J], 2005, 53: 4817

15 Cammarata R C, Sieradzki K. Physical Review Letters[J], 1989, 62: 2005

16 Hoagland R G, Kurtz R J, Henager Jr C H. Scripta Materialia[J], 2004, 50: 775

17 Meyerovich A E, Ponomarev I V. Physical Review B[J], 2002, 65: 155413

18 Aurongzeb D, Holtz M, Berg J M et al. Journal of Applied Physics[J], 2005, 98: 063708

19 Erdélyi Z, Sladecek M, Stadler L M et al. Science[J], 2004, 306: 1913

20 Stroud R M, Hanbicki A T, Park Y D et al. Physical Review Letters[J], 2002, 89: 166602

21 Zhou Q, Li Y, Wang F et al. Materials Science \& Engineering $A[\mathrm{~J}], 2016,664: 206$

22 Paul A, Lodha G S. Physical Review B[J], 2002, 65: 245416

23 Gavens A J, Heerden D V, Mann A B et al. Journal of Applied Physics[J], 2000, 87: 1255

24 Labat S, Bocquet F, Gilles B et al. Scripta Materialia[J], 2004, 50: 717

25 Spaepen F. Acta Materialia[J], 2000, 48: 31

26 Zheng J F, Walker J D, Salmeron M B et al. Physical Review Letters[J], 1994, 72: 2414

27 Wen S P, Zong R L, Zeng F et al. Acta Materialia[J], 2007, 55: 345

28 Bright A N, Thomas P J, Weyland M et al. Journal of Applied Physics[J], 2001, 89: 3143

29 Kitabjian P H, Nix W D. Acta Materialia[J], 1998, 46: 701

30 Garcia V H, Mors P M, Scherer C. Acta Materialia[J], 2000, 48: 1201

31 Suo Z, Kubair D V, Evans A G et al. Acta Materialia[J], 2003, 51: 959

32 Brantley W A. Journal of Applied Physics[J], 1973, 44: 534

33 Phillips M A, Clemens B M, Nix W D. Acta Materialia[J], 2003, 51: 3171

34 Lee S G, Kim S P, Lee K R et al. Journal of Magnetism and Magnetic Materials[J], 2005, 286: 394

35 Fonda E, Petroff F, Traverse A. Journal of Applied Physics[J], 2003, 93: 5937

36 Rothhaar U, Oechsner H, Scheib M et al. Physical Review B[J], 
2000, 61: 974

37 Lao J J, Shao N, Mei F H et al. Applied Physics Letters[J], 2005, 86: 011902
38 Wei L, Mei F H, Shao N et al. Applied Physics Letters[J], 2005, 86: 021919

\title{
不同调制结构 Ni/Al 型纳米多层膜的非对称扩散及界面应力演化行为
}

\author{
刘明霞 ${ }^{1}$, 马 $飞^{2}$, 畅庚榕 ${ }^{1}$, 何斌锋 ${ }^{1}$, 付福兴 ${ }^{1}$, 叶芳霞 ${ }^{1}$, 余历军 ${ }^{1}$, 戴 君 $^{1}$, 徐可为 ${ }^{1,2}$ \\ (1. 西安文理学院 陕西省表面工程与再制造重点实验室, 陕西 西安 710065) \\ (2. 西安交通大学 金属材料强度国家重点实验室, 陕西 西安 710049)
}

\begin{abstract}
摘 要: 为了研究分析室温下贼射沉积的金属异质结界面演化的尺度依赖性, 制备了不同调制周期和 $\mathrm{Ni}: \mathrm{Al}$ 调制比等特征结构的 $\mathrm{Ni} / \mathrm{Al}$ 型金属纳米多层膜。结合 $\mathrm{X}$ 射线衍射、多光束光学应力传感器 (MOSS) 实时薄膜曲率测量, 研究了应力演化行为, 并在此基础上分析 推测纳米多层膜在生长过程中的界面特性。结果表明, 由于各亚层内各向异性纳米晶结构, 多层膜界面具有不对称性, 这是由于界面处 $\mathrm{Ni}$ 原子向 $\mathrm{Al}$ 晶格内的不对称扩散行为所致。当此类型多层膜具备最小调制周期和最低 $\mathrm{Ni}$ : $\mathrm{Al}$ 调制比这 2 个特征参量时, 上述不对称扩 散行为由于界面累积效应变得更为加剧。
\end{abstract}

关键词：金属纳米多层膜；应力演化；不对称扩散；累积效应

作者简介: 刘明霞, 女, 1981 年生, 博士, 高级工程师, 西安文理学院机械与材料工程学院, 陕西省表面工程与再制造重点实验室, 陕西 西安 710065, E-mail: liumingxia1121@163.com 